\title{
Shooting Methods for Two-Point Boundary Value Problems of Discrete Control Systems
}

\author{
G. Kishore Babu \\ Electriacl Engineering Dept. \\ PSCMR Engineering College \\ Vijayawada, India 520002
}

\author{
M.S. Krishnarayalu, Ph.D \\ Electriacl \& Electronics Engineering Dept. \\ V R Siddhartha Engineering College \\ Vijayawada, India 520007
}

\begin{abstract}
Two-point boundary value problems (TPBVP) are an important class of problems which appear frequently in optimal control. These may be well conditioned or ill conditioned. A well- conditioned TPBVP will have a system matrix with linearly independent columns due to closeness of its eigenvalues. On the other hand an ill conditioned TPBVP will have a system matrix with almost linearly dependent columns due to wide variation of its eigenvalues. In other words, a well- conditioned system is a one- time scale system whereas an ill conditioned system is a multi-time scale system. Ill conditioned systems are computationally stiff systems with widely separated eigenvalues. The stiffness increases with increase in time scales. The solution of TPBVP of discrete control systems is obtained by shooting method, that is, a number of initial value problems (IVP) will be shot to get the solution of TPBVP. The solution of a wellconditioned TPBVP is easier compared to an ill-conditioned TPBVP. An ill-conditioned TPBVP requires orthonormalization process to make the columns of the system matrix linearly independent. More the stiffness more the number of orthonormalization processes. Here the method of complimentary functions is used for well-conditioned systems and Conte's method for ill-conditioned systems. First we develop shooting methods for well-conditioned and illconditioned TPBVP of discrete control systems. Later the methods are supported with two illustrative examples one for each case.
\end{abstract}

\section{Keywords}

Discrete control, Time-scale systems, Optimal control, Stiff two-point boundary value problem, Shooting method, Orthonormalization

\section{INTRODUCTION}

For an nth order IVP $\mathrm{n}$ initial conditions are specified along with input. Hence IVP may be solved easily by recursive method starting from the initial data and input. However for TPBVP some boundary conditions are specified at initial time and the remaining at final time (or some other time). Hence they cannot be solved easily as IVP. A well- conditioned system is that one whose system matrix columns are linearly independent and whose inverse can be obtained easily. TPBVP may be solved using standard methods for wellconditioned systems. Some solution methods for TPBVP are Interpolation methods, Variational methods, Method of Collocation, Picard's method, Discrete methods, Quasilinearization method and Shooting methods. However they may not work for ill-conditioned systems as it is. Also it is not possible to obtain a closed-form of solution practical TPBVP. Hence it is required to go for numerical methods. So much literature is available for TPBVP and multi-time scales of continuous-time systems [1-4].
Stiff two-point boundary value problems are frequently encountered in optimal control. Stiff systems are time-scalesystems or singularly perturbed systems [5-14]. The solution of two-point boundary value problems of stiff systems requires special methods such as shooting techniques. Shooting technique means finding the solution of BVP by shooting a number of IVP. Here an attempt is made to apply the same to discrete-time control systems.

\section{STATEMENT OF PROBLEM}

Consider an nth order linear shift invariant discrete system described by

$\mathrm{x}(\mathrm{k}+1)=\mathrm{Ax}(\mathrm{k})+\mathrm{Bu}(\mathrm{k})$

where

$$
\begin{aligned}
& \mathrm{x}(\mathrm{k})-\mathrm{nx} 1 \text { state vector } \\
& \mathrm{u}(\mathrm{k})-\mathrm{rx} 1 \text { control vector } \\
& \mathrm{A}-\mathrm{nxn} \text { system matrix } \\
& \mathrm{B}-\mathrm{nxr} \text { input matrix }
\end{aligned}
$$

with boundary conditions

$$
\begin{aligned}
& x_{j}(k=0)=x_{j}(0) j=1,2, \ldots, m ; \\
& x_{j}(k=N)=x_{j}(N) j=m+1, m+2, \ldots, n .
\end{aligned}
$$

$\mathrm{N}$ is an integer indicating the final time.

This TPBVP is to be solved for different conditions of system matrix A. If all the eigenvalues of $\mathrm{A}$ are close to one another it is a well-conditioned problem from computational view. If the eigenvalues of A are widely scattered it results in time-scale behavior. The multi-time scale systems exhibit the phenomenon of chaos [4] and these are ill-conditioned systems from computational view. Next shooting methods are applied for TPBVP represented by (1) for well-conditioned and ill-conditioned cases.

\subsection{Well-Conditioned TPBVP}

Method of Complementary Functions [1] will be used to solve these BVP. This method may be applicable for slightly illconditioned systems like two-time-scale systems also. Consider a discrete system described by (1) with $\mathbf{m}$ initial boundary conditions and $\mathbf{n}-\mathbf{m}$ terminal boundary conditions. Boundary conditions are: $\mathrm{x}_{1}(0), \ldots, \mathrm{x}_{\mathrm{m}}(0), \mathrm{x}_{\mathrm{m}+1}(\mathrm{~N}), \ldots$ $\mathrm{x}_{\mathrm{n}}(\mathrm{N})$; $\mathrm{N}$ is a fixed integer indicating final time. To solve the BVP, first it is required to find initial conditions corresponding to $\mathrm{x}_{\mathrm{m}+1}(\mathrm{~N}), \ldots, \mathrm{x}_{\mathrm{n}}(\mathrm{N})$. These are known as Missing Initial Conditions (MIC). Then solve the BVP as IVP using the given IC and MIC. Hence computing correct MIC is the real problem. $\mathrm{x}_{\mathrm{h}}$ and $\mathrm{x}_{\mathrm{f}}$ indicate homogeneous and forced solutions of $\mathrm{x}$. 
Step 1: Homogeneous Solutions For homogeneous solutions, Kronecker delta initial conditions are used as given below.

$$
\begin{aligned}
& x_{h}{ }^{(1)}[0]=1 \text { for } m+1 \text { else } 0 \\
& x_{h}^{(2)}[0]=1 \text { for } m+2 \text { else } 0 \\
& \cdots \\
& x_{h}^{(n-m)}[0]=1 \text { for } n \text { else } 0
\end{aligned}
$$

Shoot these IVPs and store the resulting data.

Step2: Particular solution

The initial condition for particular solution is given as

$$
\mathrm{x}_{\mathrm{f}}(0)=\left[\mathrm{x}_{1}(0) \ldots \mathrm{x}_{\mathrm{m}}(0) 0 \ldots 0\right]^{\prime}
$$

' indicates transpose. Shoot and get the forced (particular) solution from $\mathrm{x}_{\mathrm{f}}(0)$ to $\mathrm{x}_{\mathrm{f}}(\mathrm{N})$

Step 3: MIC

Here we compute the MIC

$$
\operatorname{MIC}=x_{h b}^{-1} *\left[\begin{array}{c}
x_{m+1}(N)-x_{f, m+1}(N) \\
x_{m+2}(N)-x_{f, m+2}(N) \\
\ldots \ldots \\
x_{n}(N)-x_{f, n}(N)
\end{array}\right]
$$

where

$$
x_{h b}=\left[\begin{array}{llll}
x_{h, m+1}^{(1)}(N) & x_{h, m+1}^{(2)}(N) & \ldots & x_{h, m+1}^{(n-m)}(N) \\
x_{h, m+2}^{(1)}(N) & x_{h, m+2}^{(2)}(N) & \ldots & x_{h, m+2}^{(n-m)}(N) \\
\ldots & \ldots & \ldots & \ldots \\
x_{h, n}^{(1)}(N) & x_{h, n}^{(2)}(N) & \ldots & x_{h, n}^{(n-m)}(N)
\end{array}\right]
$$

Step 4: Now solve the TPBVP as IVP using the given IC and MIC (that is shoot with IC and MIC).If MIC are accurate then the solution of $\mathrm{x}(\mathrm{k})$ satisfies all the given initial and final boundary conditions.

\subsection{Ill Conditioned TPBVP}

If the system matrix $\mathrm{A}$ is multi-time-scaled then the system becomes ill-conditioned and the columns of $\mathrm{x}_{\mathrm{hb}}$ will be almost linearly dependent. Hence $\mathrm{x}_{\mathrm{hb}}{ }^{-1}$ and MIC cannot be computed accurately. This problem can be overcome by orthonormalizing $\mathrm{x}_{\mathrm{h}}$ at appropriate values of $\mathrm{k}$. Orthonormalizaion converts almost linearly dependent vectors into linearly independent vectors. Ill-conditioned TPBVP is solved using Conte's algorithm employing complimentary functions method along with Gram-Schmidt orthonormalization process.

Gram-Schmidt orthonormalization process generates $\mathrm{N}$ orthonormal vectors $z^{(i)}, i=1,2, \ldots, N$, from a set of $\mathrm{N}$ linearly independent vectors $x^{(i)}, i=1,2, \ldots N$, by forming linear combinations of the $x^{(i)}$. The orthonormal set $z^{(i)}$ has the property

$$
\begin{aligned}
\left(z^{(j)}, z^{(i)}\right) & =1, \mathrm{j}=\mathrm{i} ; \\
& =0, \text { else }
\end{aligned}
$$

$\left(z^{(j)}, z^{(i)}\right)$ is the inner product of the vectors $z^{(j)} a n d z^{(i)}$ and is given by

$$
\left(z^{(j)}, z^{(i)}\right)=\sum_{l=1}^{N} z_{l}^{(j)} \cdot z_{l}^{(i)} .
$$

$\left\{\eta^{(i)}\right\}$ is the set of unnormalized orthogonal vectors which will be normalized to $\left\{z^{(i)}\right\}$. The transformation from the $\mathrm{x}$ 's to the z's may be expressed in partitioned matrix form as $\mathrm{Z}=\mathrm{PX}$
$\left[\begin{array}{c}Z^{(1)} \\ \vdots \\ Z^{(N)}\end{array}\right]=\left[\begin{array}{ccc}p_{11} & & \\ \vdots & \vdots & \\ p_{N 1} & p_{N 2} & \ldots p_{N N}\end{array}\right]\left[\begin{array}{c}x^{(1)} \\ \vdots \\ x^{(N)}\end{array}\right]$,

$\mathrm{Z}=\mathrm{Nx} 1$ vector, whose elements are the vectors $Z^{(N)}$,

$\mathrm{X}=\mathrm{Nx} 1$ vector, whose elements are the vectors $x^{(N)}$,

$\mathrm{P}=\mathrm{NxN}$ matrix of lower triangular form described by

$p_{j j}=1 / w_{j j} \quad \mathrm{j}=\mathrm{i}$,

$p_{j i}=\sum_{s=i}^{j-1}-\frac{\left(x^{(j)}, z^{(s)}\right)}{w_{j j}} p_{s i}, \mathrm{j}>\mathrm{i}$,

$p_{j i}=0, \quad \mathrm{j}<\mathrm{i}$,

$w_{j j}=\left(\eta^{(i)}, \eta^{(i)}\right)^{1 / 2}$.

\section{Conte's method}

This algorithm uses the method of complementary functions. It is a two-phase method. In the first phase homogeneous and forced solutions are found out recursively as IVP using Kronecker delta initial conditions at appropriate values of $\mathrm{k}$ implementing Gram-Schmidt orthonormalization process. In the second phase the MIC are found out working backward. Next working forward, find the solution of the given BVP using IC and MIC as IVP. The algorithm is similar to that of continuous-time systems [1].

Notation: Let

$\mathrm{H}^{(\mathrm{q})}(\mathrm{k})$ is an $\mathrm{nx}(\mathrm{n}-\mathrm{m})$ matrix of solutions of the homogeneous equations $\mathrm{x}_{\mathrm{h}}{ }^{(\mathrm{g}, \mathrm{q})}(\mathrm{k}), \mathrm{g}=1,2, \ldots \mathrm{n}-\mathrm{m}$, which were last orthonormalized at $\mathrm{k}^{\mathrm{q}}$, as shown below

$\mathrm{H}^{(\mathrm{q})}(\mathrm{k})=\left[\begin{array}{cccc}x_{h, 1}^{(1, q)}(k) & x_{h, 1}^{(2, q)}(k) & \ldots & x_{h, 1}^{(n-m, q)}(k) \\ x_{h, 2}^{(1, q)}(k) & x_{h, 2}^{(2, q)}(k) & \ldots & x_{h, 2}^{(n-m, q)}(k) \\ x_{h, n}^{(1, q)}(k) & x_{h, n}^{(2, .)}(k) & \ldots & x_{h, n}^{(n-m, q)}(k)\end{array}\right]$

$\mathrm{P}^{(\mathrm{q})^{\prime}}=$ transpose of $\mathrm{P}^{(\mathrm{q})},(\mathrm{n}-\mathrm{m}) \mathrm{x}(\mathrm{n}-\mathrm{m})$ matrix, which is the orthonormalization matrix of the homogeneous solutions

$\mathrm{V}^{(\mathrm{q})}(\mathrm{k})=$ the particular solution last orthogonalized at $\mathrm{k}^{\mathrm{q}}$.

\section{Algorithm:}

First phase

1. Set counter $\mathrm{q}=0$ and time $\mathrm{k}=0$. Using the Kronecker delta initial conditions compute homogeneous and particular solutions from $\mathrm{k}=0$ to $\mathrm{k}^{1}$ from steps $1 \& 2$ of well-conditioned TPBVP algorithm.

2. Set $\mathrm{q}=\mathrm{q}+1$. At $\mathrm{k}^{\mathrm{q}}$, form the set of orthonormal vectors $\mathrm{x}_{\mathrm{h}}{ }^{\mathrm{g}, \mathrm{q})}\left(\mathrm{k}^{\mathrm{q}}\right), \mathrm{g}=1,2, \ldots \mathrm{n}-\mathrm{m}$, from the set of $(\mathrm{n}-\mathrm{m})$ linearly independent vectors $\mathrm{x}_{\mathrm{h}}{ }^{(\mathrm{g}, \mathrm{q}-1)}\left(\mathrm{k}^{\mathrm{q}}\right), \mathrm{g}=1,2, \ldots \mathrm{n}-\mathrm{m}$. In matrix form

$$
\mathrm{H}^{(\mathrm{q})}\left(\mathrm{k}^{\mathrm{q}}\right)=\mathrm{H}^{(\mathrm{q}-1)}\left(\mathrm{k}^{\mathrm{q}}\right) \mathrm{P}^{(\mathrm{q})}
$$

3. At $\mathrm{k}^{\mathrm{q}}$, form the orthogonal complement of $\mathrm{V}^{(\mathrm{q}-1)}\left(\mathrm{k}^{\mathrm{q}}\right)$ by subtracting out a linear combination of the orthonormal homogeneous vectors $\mathrm{x}_{\mathrm{h}}{ }^{(\mathrm{g}, \mathrm{q})}\left(\mathrm{k}^{\mathrm{q}}\right), \mathrm{g}=1,2, \ldots \mathrm{n}-\mathrm{m}$; as

$\mathrm{V}^{(\mathrm{q})}\left(\mathrm{k}^{\mathrm{q}}\right)=\mathrm{V}^{(\mathrm{q}-1)}\left(\mathrm{k}^{\mathrm{q}}\right)-\mathrm{H}^{(\mathrm{q})}\left(\mathrm{k}^{\mathrm{q}}\right) \omega^{(\mathrm{q})}$

where $\omega^{(\mathrm{q})}=\mathrm{n}-\mathrm{m} \times 1$ vector with components

$\omega_{1}{ }^{(\mathrm{q})}, \omega_{2}{ }^{(\mathrm{q})}, \ldots, \omega_{\mathrm{n}-\mathrm{m}}{ }^{(\mathrm{q})}$,

$\omega_{\mathrm{g}}{ }^{(\mathrm{q})}=\left(\mathrm{V}^{(\mathrm{q}-1)}\left(\mathrm{k}^{\mathrm{q}}\right), \mathrm{x}_{\mathrm{h}}{ }^{(\mathrm{g}, \mathrm{q})}\left(\mathrm{k}^{\mathrm{q}}\right)\right)$.

4. Compute recursively from $\mathrm{k}^{\mathrm{q}}$ to $\mathrm{k}^{\mathrm{q}+1}$ the $(\mathrm{n}-\mathrm{m})$ homogeneous equations starting with vectors at $\mathrm{k}^{\mathrm{q}}$, 
$\mathrm{x}_{\mathrm{h}}{ }^{\mathrm{g}, \mathrm{q})}\left(\mathrm{k}^{\mathrm{q}}\right), \mathrm{g}=1,2, \ldots \mathrm{n}-\mathrm{m}$. Also compute particular solution from $\mathrm{k}^{\mathrm{q}}$ to $\mathrm{k}^{\mathrm{q}+1}$ starting with $\mathrm{V}^{(\mathrm{q})}\left(\mathrm{k}^{\mathrm{q}}\right)$.

5. If $\mathrm{k}^{\mathrm{q}}<\mathrm{N}$ go to step 2 .

6. At $\mathrm{k}=\mathrm{N}$ execute steps 2 and 3 . Here let $\mathrm{Q}=\mathrm{q}+1$ and $\mathrm{k}^{\mathrm{Q}}$ $=\mathrm{N}$

Second Phase

7. The general solution at $\mathrm{N}$ is given as the sum of the particular solution plus a linear combination of the homogeneous solutions.

$\mathrm{x}\left(\mathrm{k}^{\mathrm{Q}}\right)=\mathrm{V}^{(\mathrm{Q})}\left(\mathrm{k}^{\mathrm{Q}}\right)+\mathrm{H}^{(\mathrm{Q})}\left(\mathrm{k}^{\mathrm{Q}}\right) \beta^{\mathrm{Q}}$ corresponding to $\mathrm{n}-\mathrm{m}$ terminal boundary conditions.

Solving $\beta^{\mathrm{Q}}=\mathrm{H}^{(\mathrm{Q})}\left(\mathrm{k}^{\mathrm{Q}}\right)^{-1}\left[\mathrm{x}\left(\mathrm{k}^{\mathrm{Q}}\right)-\mathrm{V}^{(\mathrm{Q})}\left(\mathrm{k}^{\mathrm{Q}}\right)\right]$.

$\beta^{\mathrm{Q}}=(\mathrm{n}-\mathrm{m}) \times 1$ vector of constants with components

$\beta_{1}{ }^{(\mathrm{Q})}, \beta_{2}{ }^{(\mathrm{Q})}, \ldots, \beta_{\mathrm{n}-\mathrm{m}}{ }^{(\mathrm{Q})}$.

8. The MIC corresponding to $n-m$ terminal boundary conditions is constructed by working backward from $\mathrm{N}$ as

$\beta^{(\mathrm{q}-1)}=\mathrm{P}^{(\mathrm{q})}{ }^{\prime}\left[\beta^{(\mathrm{q})}-\omega^{(\mathrm{q})}\right], \mathrm{q}=\mathrm{Q}, \mathrm{Q}-1, \ldots, 1$.

where $\mathrm{P}^{(\mathrm{q})}$, and $\omega^{(\mathrm{q})}$ have been computed in first phase.

$\beta^{(0)}$ is the MIC.

9. Perform final shoot with given IC and MIC to get the required solution of TPBVP.

\section{ILLUSTRATIVE EXAMPLES}

Two examples are provided in support of the shooting methods for TPBVP; one for well-conditioned discrete control system which does not require orthonormolization and other for ill-conditioned discrete control system which requires orthonormolization. The results are given in tabular form.

\subsection{Example I}

Consider the third order single area power system model used for LFC sampled with $0.2 \mathrm{~s}$ [12]. The resulting system is given by

$$
\begin{aligned}
& {\left[\begin{array}{c}
x_{01}(k+1) \\
x_{02}(k+1) \\
x_{1}(k+1)
\end{array}\right]=\left[\begin{array}{ccc}
0.772 & 0.037 & -0.017 \\
0.085 & 0.720 & 0.0406 \\
-0.244 & 0.145 & 0.0306
\end{array}\right]\left[\begin{array}{c}
x_{01}(k) \\
x_{02}(k) \\
x_{1}(k)
\end{array}\right]+} \\
& {\left[\begin{array}{c}
-0.144 \\
0.074 \\
0.705
\end{array}\right] \mathrm{u}(\mathrm{k})}
\end{aligned}
$$

Here $x_{0}=\left[\begin{array}{l}x_{01} \\ x_{02}\end{array}\right]$ and $\mathrm{u}(\mathrm{k})$ is unit step function. The Eigen spectrum of this system

\section{$(0.8078,0.6992,0.0156)$}

clearly indicates two-time-scale nature with two slow modes represented by $\mathrm{x}_{0}$ and one fast mode represented by $\mathrm{x}_{1}$.

The boundary conditions are given as

$\mathrm{x}_{01}(10)=1 ; \quad \mathrm{x}_{02}(10)=1 ; \quad \mathrm{x}_{1}(0)=10$.

Here $n=3$ and $m=1$. By applying the shooting method of well-conditioned systems developed in Section 2.1, the solution obtained from MATLAB programming is given below. Please note that all the boundary conditions are satisfied.

Step 1: Homogeneous solutions

$\mathrm{x}_{\mathrm{h}}^{(1)}[0]=[1 ; 0 ; 0]$ using MATLAB notation $\mathrm{x}_{\mathrm{h}}^{(2)}[0]=[0 ; 1 ; 0]$

The resulting final values at $\mathrm{k}=10$, after shooting, are

$$
\begin{aligned}
& \mathrm{x}_{\mathrm{h}}{ }^{(1)}[10]=[0.0932 ; 0.0596 ;-0.0191] \\
& \mathrm{x}_{\mathrm{h}}{ }^{(2)}[10]=[0.0278 ; 0.0524 ; 0.0021]
\end{aligned}
$$

Step2: Particular solution

The initial condition for particular solution is given as

$$
\mathrm{x}_{\mathrm{f}}(0)=[0 ; 0 ; 10]
$$

The resulting final values at $\mathrm{k}=10$, after shooting, are

$$
\mathrm{x}_{\mathrm{f}}(10)=[-0.6183 ; 0.2430 ; 0.9185]
$$

Step 3: MIC

The resulting $x_{h b}$ and MIC are

$$
\begin{aligned}
& x_{h b}=\left[\begin{array}{ll}
0.0932 & 0.0278 \\
0.0596 & 0.0524
\end{array}\right] \\
& \mathrm{MIC}=[19.7476 ;-7.9997]
\end{aligned}
$$

Step 4: Shoot with initial conditions and MIC

$$
\mathrm{x}_{01}(0)=19.7476 ; \quad \mathrm{x}_{02}(0)=-7.9997 ; \quad \mathrm{x}_{1}(0)=10 .
$$

The resulting solution is shown in Table1. As seen from this table all boundary conditions $\mathrm{x}_{01}(10)=1, \mathrm{x}_{02}(10)=1, \mathrm{x}_{1}(0)=$ 10 (indicated in boldface) are satisfied. Hence this is the solution of given TPBVP. The same results are displayed in Fig. 1 giving picturesque view.

Table 1 - TPBVP solution for well-conditioned system

\begin{tabular}{|c|c|c|c|}
\hline $\mathrm{x}(\mathrm{k})$ & $\begin{array}{c}\text { Exact } \\
\text { Solution }\end{array}$ & $\mathrm{x}(\mathrm{k})$ & $\begin{array}{c}\text { Exact } \\
\text { Solution }\end{array}$ \\
\hline$x_{01}(0)$ & 19.7476 & $x_{01}(6)$ & 3.6438 \\
\hline$x_{02}(0)$ & -7.9997 & $x_{02}(6)$ & 1.1480 \\
\hline$x_{1}(0)$ & $\mathbf{1 0 . 0 0 0 0}$ & $x_{1}(6)$ & -0.3609 \\
\hline$x_{01}(1)$ & 14.6350 & $x_{01}(7)$ & 2.7175 \\
\hline$x_{02}(1)$ & -3.6005 & $x_{02}(7)$ & 1.1964 \\
\hline$x_{1}(1)$ & -4.9666 & $x_{1}(7)$ & -0.0279 \\
\hline$x_{01}(2)$ & 11.1054 & $x_{01}(8)$ & 1.9986 \\
\hline$x_{02}(2)$ & -1.4752 & $x_{02}(8)$ & 1.1661 \\
\hline$x_{1}(2)$ & -3.5392 & $x_{1}(8)$ & 0.2153 \\
\hline$x_{01}(3)$ & 8.4348 & $x_{01}(9)$ & 1.4383 \\
\hline$x_{02}(3)$ & -0.1871 & $x_{02}(9)$ & 1.0930 \\
\hline$x_{1}(3)$ & -2.3261 & $x_{1}(9)$ & 0.3938 \\
\hline$x_{01}(4)$ & 6.4002 & $x_{01}(10)$ & $\mathbf{1 . 0 0 0 0}$ \\
\hline$x_{02}(4)$ & 0.5626 & $x_{02}(10)$ & $\mathbf{1 . 0 0 0 0}$ \\
\hline$x_{1}(4)$ & -1.4506 & $x_{1}(10)$ & 0.5254 \\
\hline$x_{01}(5)$ & 4.8423 & & \\
\hline$x_{02}(5)$ & 0.9650 & & \\
\hline$x_{1}(5)$ & -0.8187 & & \\
\hline & & & \\
\hline & & & \\
\hline
\end{tabular}




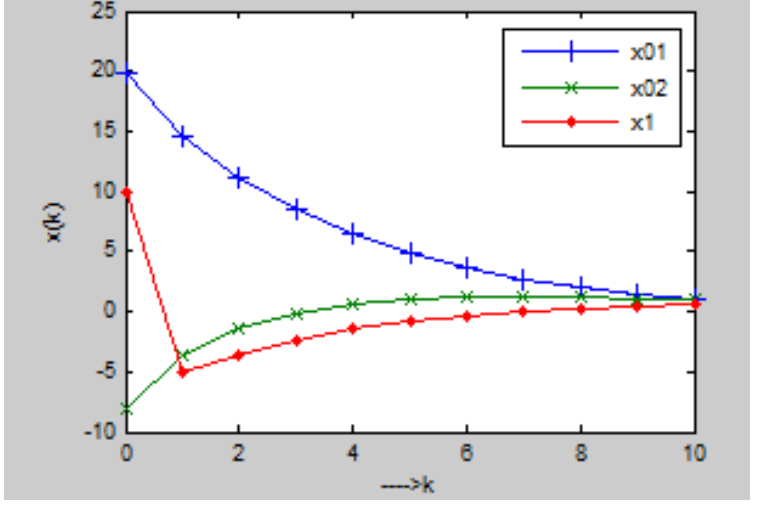

Fig. 1 Solution of Illustrative Example I

\subsection{Example II}

Consider the TPBVP resulting from two-parameter optimal control [14]

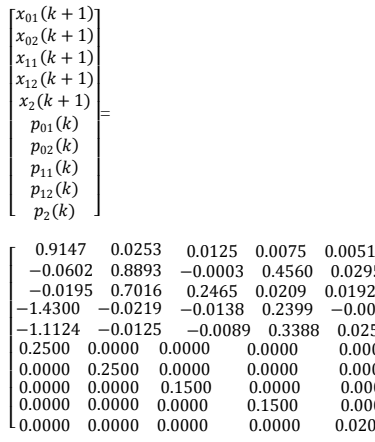

$\left.\begin{array}{lllll}-0.0000 & -0.0005 & -0.00002 & -0.0029 & -0.0002 \\ -0.0005 & -0.0037 & -0.00024 & -0.0184 & -0.0014\end{array}\right]$ $\begin{array}{lllll}-0.0005 & -0.0037 & -0.00024 & -0.0184 & -0.0014 \\ -0.0001 & -0.0012 & -0.00006 & -0.0059 & -0.0004\end{array}$ $\begin{array}{lllll}-0.0145 & -0.0924 & -0.00594 & -0.0059 & -0.0004 \\ -0.0345 & -0.0346\end{array}$ $\begin{array}{lllll}-0.0111 & -0.0711 & -0.0045 & -0.3465 & -0.0266\end{array}$ $\begin{array}{lllll}0.9147 & -0.0602 & -0.0039 & -0.2860 & -0.0222\end{array}$ $\begin{array}{lllll}0.0253 & 0.8893 & 0.1403 & -0.0043 & -0.0002 \\ 0.0625 & -0.0015 & 0.2465 & -0.0438 & -0.009\end{array}$ $\begin{array}{ccccc}0.0625 & -0.0015 & 0.2465 & -0.0138 & -0.0009 \\ 0.0375 & 0.2280 & 0.0209 & 0.2399 & 0.0338\end{array}$ $\begin{array}{lllll}0.2550 & 1.47500 & 0.1920 & -0.0630 & 0.0259\end{array}$

with boundary conditions

$\mathrm{x}_{01}(0)=2 ; \quad \mathrm{x}_{02}(0)=-1 ; \mathrm{x}_{10}(0)=1 ; \mathrm{x}_{12}(0)=5 ; \mathrm{x}_{2}(0)=-4$ and $\mathrm{p}_{01}(6)=0 ; \mathrm{p}_{02}(6)=0 ; \mathrm{p}_{11}(6)=0 ; \mathrm{p}_{12}(6)=0 ; \mathrm{p}_{2}(6)=0$

Eigen values of this TPBVP are

$\{33.84855 ; 4.08196 \pm 0.40125 \mathrm{i} ; 1.13125 \pm 0.10143 \mathrm{i}$;

$0.87692 \pm 0.07862 \mathrm{i} ; 0.242635 \pm 0.02385 \mathrm{i} ; 0.029543$ \}

This clearly indicates stable and unstable slow, fast and faster modes. This system is a true multi-time-scale system with chaotic behavior exhibiting butterfly phenomenon. The optimal solution is obtained by Conte's method as mentioned in Section 2.2 Ill-conditioned TPBVP. The result is shown below in Table 2 for this numerical method. Also it is displayed pictorially in Figures 2 and 3 for quick view. Fig. 2 shows the solution of states $\mathrm{x}(\mathrm{k})$ whereas Fig. 3 displays the solution of co-states $\mathrm{p}(\mathrm{k})$.

Table 2 - TPBVP solution for ill-conditioned system

\begin{tabular}{|c|c|c|c|}
\hline $\mathrm{x}(\mathrm{k}) \& \mathrm{p}(\mathrm{k})$ & $\begin{array}{l}\text { Optimal } \\
\text { Solution }\end{array}$ & $\mathrm{x}(\mathrm{k}) \& \mathrm{p}(\mathrm{k})$ & $\begin{array}{c}\text { Optimal } \\
\text { Solution }\end{array}$ \\
\hline $\mathrm{x}_{01}(0)$ & $\mathbf{2 . 0 0 0 0 0}$ & $\mathrm{p}_{01}(3)$ & 1.16381 \\
\hline $\mathrm{x}_{02}(0)$ & $\mathbf{- 1 . 0 0 0 0 0}$ & $\mathrm{p}_{02}(3)$ & -0.84362 \\
\hline $\mathrm{x}_{11}(0)$ & $\mathbf{1 . 0 0 0 0 0}$ & $\mathrm{p}_{11}(3)$ & -0.14593 \\
\hline
\end{tabular}

\begin{tabular}{|c|c|c|c|}
\hline $\mathrm{x}_{12}(0)$ & 5.00000 & $\mathrm{p}_{12}(3)$ & -0.63653 \\
\hline $\mathrm{x}_{2}(0)$ & -4.00000 & $\mathrm{p}_{2}(3)$ & -0.82417 \\
\hline $\mathrm{p}_{01}(0)$ & 2.86755 & $\mathrm{x}_{01}(4)$ & 1.24857 \\
\hline $\mathrm{p}_{02}(0)$ & -1.11978 & $\mathrm{x}_{02}(4)$ & -1.24329 \\
\hline $\mathrm{p}_{11}(0)$ & 0.31332 & $\mathrm{x}_{11}(4)$ & -1.14097 \\
\hline $\mathrm{p}_{12}(0)$ & 0.43092 & $\mathrm{x}_{12}(4)$ & -2.32278 \\
\hline $\mathrm{p}_{2}(0)$ & -1.02475 & $\mathrm{x}_{2}(4)$ & -2.27450 \\
\hline $\mathrm{x}_{01}(1)$ & 1.83594 & $\mathrm{p}_{01}(4)$ & 0.66903 \\
\hline $\mathrm{x}_{02}(1)$ & -0.88573 & $\mathrm{p}_{02}(4)$ & -0.62869 \\
\hline $\mathrm{x}_{11}(1)$ & -0.46181 & $\mathrm{p}_{11}(4)$ & -0.19641 \\
\hline $\mathrm{x}_{12}(1)$ & -1.27960 & $\mathrm{p}_{12}(4)$ & -0.49655 \\
\hline $\mathrm{x}_{2}(1)$ & -0.36337 & $\mathrm{p}_{2}(4)$ & -0.49148 \\
\hline $\mathrm{p}_{01}(1)$ & 2.32156 & $\mathrm{x}_{01}(5)$ & 1.06844 \\
\hline $\mathrm{p}_{02}(1)$ & -1.05230 & $\mathrm{x}_{02}(5)$ & -1.34642 \\
\hline $\mathrm{p}_{11}(1)$ & 0.03291 & $\mathrm{x}_{11}(5)$ & -1.26783 \\
\hline $\mathrm{p}_{12}(1)$ & -0.55425 & $\mathrm{x}_{12}(5)$ & -2.11286 \\
\hline $\mathrm{p}_{2}(1)$ & -1.00144 & $\mathrm{x}_{2}(5)$ & -2.07634 \\
\hline $\mathrm{x}_{01}(2)$ & 1.64240 & $\mathrm{p}_{01}(5)$ & 0.26711 \\
\hline $\mathrm{x}_{02}(2)$ & -0.94998 & $\mathrm{p}_{02}(5)$ & -0.33660 \\
\hline $\mathrm{x}_{11}(2)$ & -0.79927 & $\mathrm{p}_{11}(5)$ & -0.19017 \\
\hline $\mathrm{x}_{12}(2)$ & -2.48652 & $\mathrm{p}_{12}(5)$ & -0.31693 \\
\hline $\mathrm{x}_{2}(2)$ & -2.14862 & $\mathrm{p}_{2}(5)$ & -0.04152 \\
\hline $\mathrm{p}_{01}(2)$ & 1.72688 & $\mathrm{x}_{01}(6)$ & 0.90095 \\
\hline $\mathrm{p}_{02}(2)$ & -0.97576 & $\mathrm{x}_{02}(6)$ & -1.41891 \\
\hline $\mathrm{p}_{11}(2)$ & -0.07234 & $\mathrm{x}_{11}(6)$ & -1.36202 \\
\hline $\mathrm{p}_{12}(2)$ & -0.70535 & $\mathrm{x}_{12}(6)$ & -1.97468 \\
\hline $\mathrm{p}_{2}(2)$ & -0.99976 & $\mathrm{x}_{2}(6)$ & -1.93003 \\
\hline $\mathrm{x}_{01}(3)$ & 1.44111 & $\mathrm{p}_{01}(6)$ & 0.00000 \\
\hline $\mathrm{x}_{02}(3)$ & -1.10474 & $\mathrm{p}_{02}(6)$ & 0.00000 \\
\hline $\mathrm{x}_{11}(3)$ & -0.98380 & $\mathrm{p}_{11}(6)$ & 0.00000 \\
\hline $\mathrm{x}_{12}(3)$ & -2.52265 & $\mathrm{p}_{12}(6)$ & 0.00000 \\
\hline $\mathrm{x}_{2}(3)$ & -2.41595 & $\mathrm{p}_{2}(6)$ & 0.00000 \\
\hline
\end{tabular}

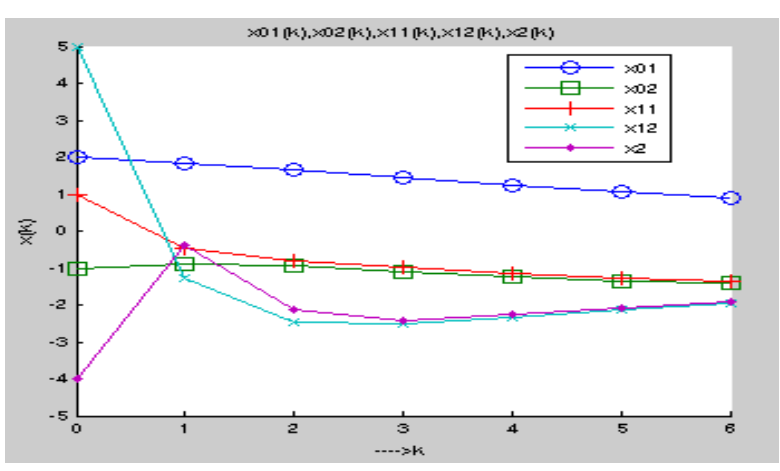

Fig. 2 Solution of States $x(k)$ of Illustrative Example II 


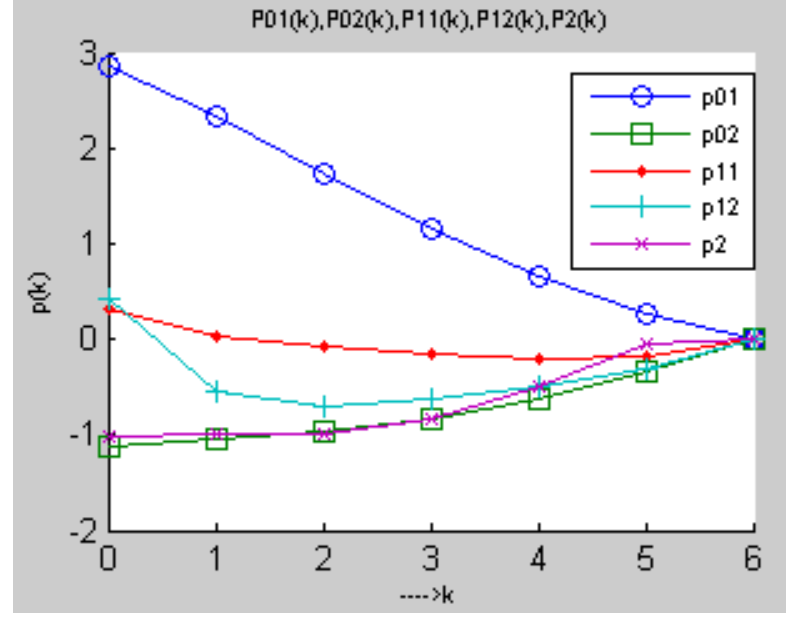

Fig. 3 Solution of Co-States p(k) of Illustrative Example II

\section{CONCLUSIONS}

TPBVP occur in many engineering problems like optimal control. TPBVP solution is not easy as the response has to satisfy both the initial and terminal boundary conditions. Their solution is easy for well-conditioned systems compared to ill-conditioned systems. These methods are available for continuous systems. Here they are presented for discrete control systems with two illustrative examples one for wellconditioned and one for ill-conditioned TPBVP. Method of complimentary functions is used for well conditioned TPBVP. Ill-conditioned TPBVP is solved using Conte's method employing complimentary functions method along with Gram-Schmidt orthonormalization process. Start with orthonormalizing at $\mathrm{k}=\mathrm{N}$. If it is not yielding accurate MIC and TPBVP solution, then orthonomalize at $\mathrm{k}=\mathrm{N} / 2$ and $\mathrm{N}$ for even $\mathrm{N}$. If this also not yielding the required TPBVP solution then orthonormalize at $\mathrm{k}=\mathrm{N} / 4,2 \mathrm{~N} / 4, \ldots$ and $\mathrm{N}$ for even $\mathrm{N}$. And so on. Similar selection may be employed for odd N. The numbers of orthonormaliztions depend upon the degree of ill-condition of A matrix. If the system is more ill-conditioned more the number of orthonormaliztions required.

\section{ACKNOWLEDGMENTS}

We greatly acknowledge Siddhartha Academy of General and Technical Education, Vijayawada for providing the facilities to carry out this research.

\section{REFERENCES}

[1] Roberts S.M. and Shipman J.S. (1972) Two-point Boundary Value Problems: Shooting Methods. Elsevier, New York.

[2] SUNG N. HA, "A Nonlinear Shooting Method for TwoPoint Boundary Value Problems" Computers and Mathematics with Applications 42 (2001) 1411-1420.
[3] Dinkar Sharma, Ram Jiwari, SheoKumar, "Numerical Solution of Two Point Boundary Value Problems Using Galerkin-Finite Element Method" ISSN 1749-3889 (print), 1749-3897 (online) International Journal of Nonlinear Science Vol.13(2012) No.2,pp.204-210.

[4] Koichi F. and Kunihiko K. (2003). Bifurcation cascade as chaotic itinerancy with multiple time scales. Chaos: An Interdisciplinary Journal of Nonlinear Science, 13, 1041-1056.

[5] Naidu D. S. (2002), Singular Perturbations and Time Scales in Control Theory and Applications: An Overview. Dynamics of Continuous, Discrete \& Impulsive Systems, 9, 2, 233-278.

[6] Naidu, D.S and Rao, A.K. (1985), Singular perturbation analysis of discrete control systems. Volume 1154 of Lecture Notes in Mathematics, A.Dold and B. Eckmann, eds, Springer-Verlag.

[7] Naidu, D.S and D.B Price (1988), Singular perturbations and time scales in the design of digital flight control systems. NASA Technical paper 2844.

[8] Krishnarayalu M. S. (1989), Singular perturbation method applied to the open-loop discrete optimal control problem with two small parameters. Int. J. Systems Science, 20, 5, 793-809.

[9] Krishnarayalu M. S. (1994), Singular perturbation analysis of a class of initial and boundary value problems in multiparameter digital control systems. ControlTheory and Advanced Technology, 10, 3, 465-477.

[10] Krishnarayalu M. S. (1999), Singular perturbation methods for one-point, two-point and multi-point boundary value problems in multiparameter digital control systems. Journal of Electrical and Electronics Engineering, Australia, 19, 3, 97-110.

[11] Krishnarayalu M. S. (2008), Singular perturbation method applied to the discrete Euler-Lagrange freeendpoint optimal control problem. Automatic Control (theory and applications) AMSE journal, 63, 3, 16-29.

[12] Kishore Babu G. and Krishnarayalu M. S.(2014) Some Applications of Discrete One Parameter Singular Perturbation Method. JCET Vol. 4 Iss.1, PP. 76-81.

[13] Calovic, M. (1971), Dynamic State Space Models of Electric Power Systems(Urbana: University of Illinois Press).

[14] Kishore Babu G. and Krishnarayalu M. S.(2014) "Suboptimal Control of Singularly Perturbed Two Parameter Discrete Control System" International Electrical Engineering Journal (IEEJ) Vol. 5 (2014) No.11, pp. 1594-1604, ISSN 2078-2365. 